Diabetologia 11, 221-224 (1975)

(C) by Springer-Verlag 1975

\title{
Increased Kidney Size and Glomerular Filtration Rate in Untreated Juvenile Diabetes: Normalization by Insulin-Treatment
}

\author{
C. E. Mogensen and M. J. F. Andersen \\ Second Clinic of Internal Medicine and the Roentgen Diagnostic Department, University of Aarhus, Kommunehospitalet, \\ Aarhus, Denmark \\ Received: December 9, 1974, and in revised form: March 19, 1975
}

\begin{abstract}
Summary. Glomerular filtration rate (GFR), renal plasma flow (RPF) and roentgenographic kidney size were measured in six newly diagnosed male diabetics with a mean age of 25 years. Glomerular filtration rate was elevated before treatment to the same extent as found previously. A significant fall in both kidney size and glomerular filtration rate was found after treatment with insulin for 3 months. These results
\end{abstract}

support further the concept that there is a basal connection between enlarged kidneys and the elevated GFR of early diabetes.

Key words: Glomerular filtration rate, renal plasma flow, kidney size, insulin treatment, diabetes mellitus.
We have recently demonstrated that the increased glomerular filtration rate found in early juvenile diabetes is associated with increased kidney size. Furthermore a significant correlation between kidney size and kidney function, as measured by glomerular filtration rate (GFR) and renal plasma flow (RPF) was evident both in normal and diabetic subjects [15]. Since the abnormal glomerular filtration rate is reversible by strict insulin treatment $[9,13]$, it was considered of interest to examine whether a reduction of kidney size could be demonstrated in newly diagnosed diabetics along with the fall in GFR that occurs after a few months of insulin treatment.

\section{Materials and Methods}

\section{Subjects Investigated}

Six young male patients with newly diagnosed diabetes mellitus aged 21 to 29 years were examined. The patients had moderate symptoms of diabetes but they had been working normally until admission to the clinic. They all had normal total- $\mathrm{CO}_{2}$ in plasma, but clearly elevated plasma glucose values, $257.7 \mathrm{mg} /$ $100 \mathrm{ml} \pm 22.3$ (SD), gross glucosuria, and ketonuria. Data are given on Table 1.

The patients were examined before insulin treatment and again 3 months after initiation of treatment.

\section{Kidney Function Tests}

GFR and RPF were measured by I-125 iothalamate and by 131-I-hippuran clearance respectively, using a constant infusion technique as described in detail previously [10]. Four clearance periods lasting twenty minutes were performed in each test. Results were corrected to $1.73 \mathrm{~m}^{2}$ body surface. The tests were performed in the morning on patients in the fasting state. When examined during insulin treatment the patients had been given their last insulin injection in the morning or afternoon of the day before the clearance test.

The size of the kidneys was measured on intravenous pyelograms taken with ureteric compression as described earlier [15]. The following measurements were obtained: length - greatest distance from pole to pole, in centimeters; width - greatest distance from lateral kidney surface to tangent line of medial borders of the kidney, in centimeters; kidney area index - sum of product of length and width, in square centimeters, for both kidneys. Kidney weight was calculated on the basis of data presented by Moëll [8].

\section{Results}

The results of kidney function tests and measurements of the roentgenographic kidney sizes are given in table 1 . There was a significant fall in both GFR and kidney size after treatment. GFR before treatment was $142.7 \pm 9.7 \mathrm{ml} / \mathrm{min}$, after treatment $129.0 \pm$ $10.2 \mathrm{ml} / \mathrm{min}$. Calculated kidney weight, corrected to $1.73 \mathrm{~m}^{2}$ body surface was $373.8 \pm 31.8$ before treatment and after treatment $332.8 \pm 33.0 \mathrm{~g}$. In both instances the fall is significant using the method of paired comparison $(P<0.01)$. The percentage fall in GFR 


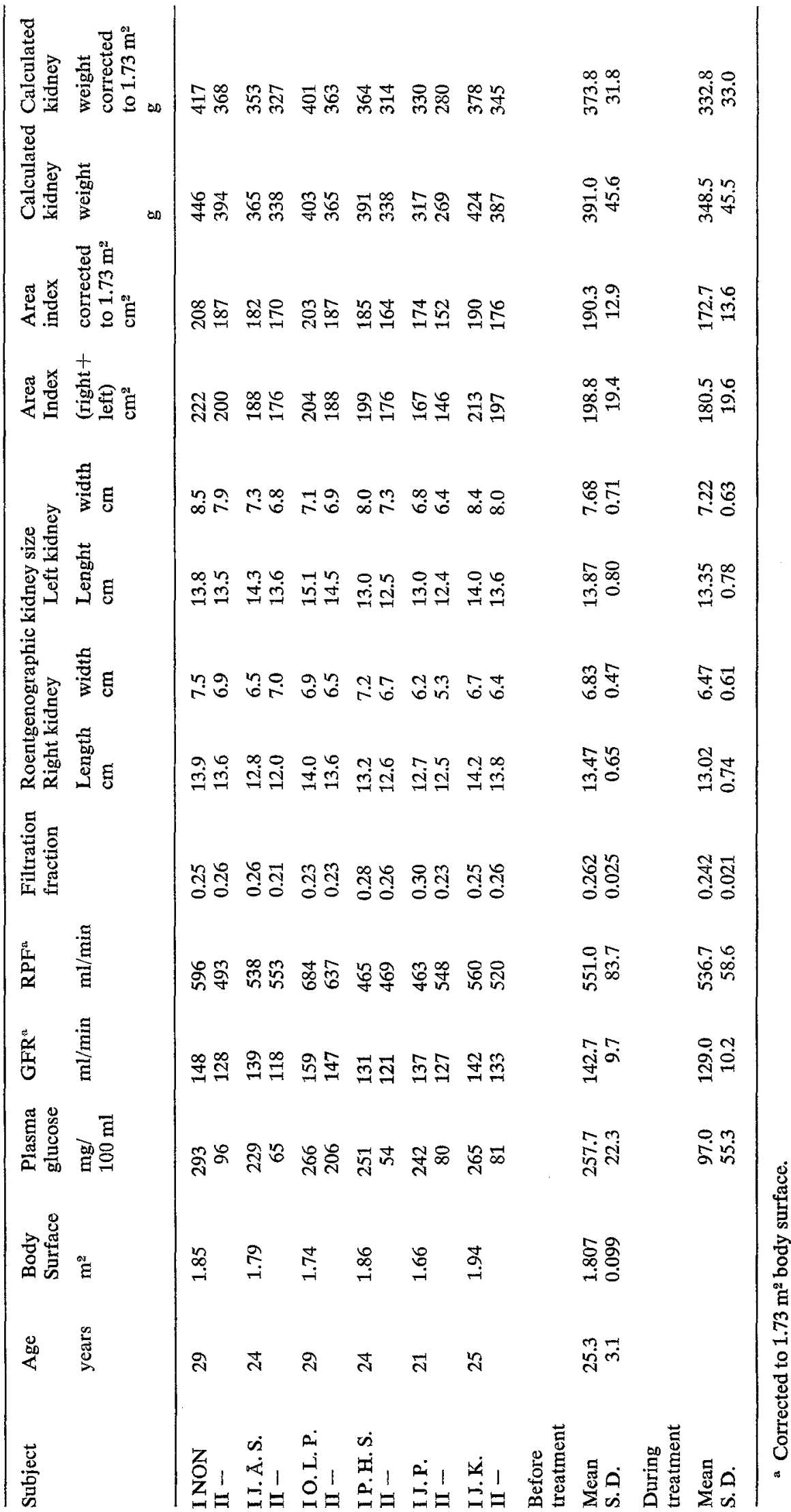


was 12 and the percentage decrease in kidney size was similar, namely 13 . The mean plasma glucose before the clearance test during treatment was $97 \mathrm{mg}$ / $100 \mathrm{ml} \pm 55.3$ (SD).

Fig. 1 shows kidney weight plotted against GFR in the six subjects.

\section{Discussion}

As recently surveyed [13] a number of studies have shown that GFR is increased in juvenile diabetics before the onset of clinical nephropathy $[1,3$, $4,9,10,11,12,14,15,17]$. It has also been shown that this abnormality is reversible. After a few weeks of intensive insulin treatment of newly diagnosed diabetics, the high GFR-values were seen to decline to normal or nearly normal values [9]. The present study

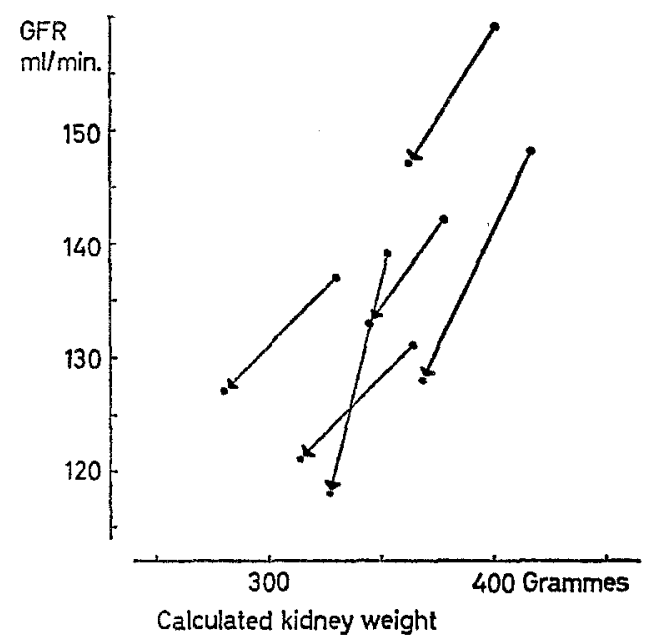

Fig. 1. GRF and calculated kidney weight in 6 newly diagnosed diabetics before and 3 months after start of insulin treatment

demonstrates that the kidney size is increased in untreated juvenile diabetes to the same extent as earlier found in insulin-treated diabetics with a duration of diabetes of $1-12$ years [15].

As also shown in the present study this anatomical abnormality was reversible, since a significant fall in kidney size, to approximately normal level was found after strict insulin treatment for about 3 months, in parallel with the fall in GFR. There was no constant change in RPF and RPF was not increased. Thus the abnormalities cannot be secondary to a change in renal plasma flow. It is remarkable that patients who have been treated with standard insulin regimes for $1-12$ years show approximately the same increase in kidney size as do newly diagnosed diabetics [15].
This is probably explained by the fact that during the the first months or the first year of insulin regimes normalization of blood sugar values is generally easier than in patients with diabetes of longer duration. The size of the kidney or renal function (as measured by GFR) may be useful as a parameter of long term regulation; normalization of kidney size is, however, not generally possible in patients who have had diabetes for a number of years.

The structures in the kidney that undergo changes during insulin treatment remain to be clarified. It has been demonstrated that the glomerular tuft is significantly increased in size in early diabetes [16]. However, the glomeruli occupy only a very small portion of the volume of the kidney and therefore tubular and/or intercellular structures must also be increased in size. In this connection it is interesting to note that tubular function, as measured by maximal tubular reabsorption capacity for glucose, is increased in short-term diabetes to the same extent as the GFR [11]. This increase in tubular function may reflect increase in tubular cell size. The observed increase in kidney size may be related to glycogen deposition in the tubular cells, the long-known Armanni-Ebstein lesion [7]. However to our knowledge, no information on tubular cell size in diabetes is available in the literature.

It seems most likely that the changes observed were induced by long-term elevation of blood sugar values. No variation was seen in GFR during acute elevation of plasma-glucose in diabetics [12] and furthermore GFR was found high and non-dependent of plasma glucose measured during clearance experiments in 38 diabetics with diabetes of $1-12$ years duration; that is years after the initial normalization of blood sugar values [14]. It would also seem highly unlikely that kidney size would change during acute alteration in plasma glucose.

The present and our recent study on kidney size in diabetes [15] indicate that increased kidney size is the main mechanism behind the high GFR in these patients, but since a high filtration fraction was also found, increased filtration pressure could also be of importance.

The mediation for the increased kidney size in diabetes is not clear. It could be a result of longterm hyperglycaemia with subsequent increased tubular reabsorption of glucose which may lead to cellular hypertrophy. Mechanisms which maintain glomerulartubular balance may thereafter induce increased GFR. Increased growth hormone secretion found in juvenile diabetes [6] may also be of importance. Injection of growth hormone for several days is known to increase GFR as well as RPF in normal subjects [2]. Remark- 
able increases in kidney size have been found in acromegaly [5]. Ditzel and Junker [3] did not find a correlation between serum growth hormone and kidney function in diabetic patients. However, it should be considered that the serum growth hormone the days before the test might be more relevant, since growth hormone needs to be given for some days to produce an effect on kidney function. We have earlier presented evidence indicating that increased growth hormone secretion may be important [13]. However, increased RPF was not found in the present patients and in previous studies, normal or only slightly increased RPF was found. Other factors must therefore also be of importance [13].

Acknowledgement. Mrs. Bodil Willumsen is thanked for skilful technical assistance. The study was supported by Statens Lægevidenskabelige Forskningråd.

\section{References}

1. Cambier, P.: Application de la théorie de Rehberg a l'etude clinique des affections rénales et du diabete. Ann. med. Nancy 35, 273-299 (1934)

2. Corvilain, J., Abramow, M.: Some effects of human growth hormone on renal hemodynamics and on tubular phosphate transport in man. J. clin. Invest. 41, 1230-1235 (1962)

3. Ditzel, J., Schwartz, M.: Abnormally increased glomerular filtration rate in short-term insulin-treated diabetic subjects. Diabetes 16, 264-267 (1967)

4. Ditzel, J., Junker, K.: Abnormal glomerular filtration rate, renal plasma flow, and renal protein excretion in recent and short-term diabetics. Brit. med. J. 1972 II, 13-19

5. Gershberg, H., Heinemann, H. O., Stumf, H. H.: Renal function studies and autopsy report in a patient with gigantism and acromegaly. J. clin. Endocr. 17, 377-385 (1957)

6. Hansen, A. P.: Abnormal serum growth hormone response to exercise in juvenile diabetics. J. clin. Invest. 49, 13671478 (1970)

7. Kimmelstiel, P.: Diabetic nephropathy in: structural basis of renal disease, (ed E. Lovell Becker, Hoeber Medical Division) New York 1968

8. Möell, H.: Kidney size and its deviation from normal in acute renal failure. Acta radiol. (Stockh.) Suppl. 206 (1961)

9. Mogensen, C. E.: Kidney function and glomerular permeability to macromolecules in early juvenile diabetes. Scand. J. clin. Lab. Invest. 28, 79-90 (1971)

10. Mogensen, C. E.: Glomerular filtration rate and renal plasma flow in short-term and long-term juvenile diabetes. Scand. J. clin. Lab. Invest. 28, 91-100 (1971)

11. Mogensen, C. E.: Maximum tubular reabsorption capacity for glucose and renal hemodynamics during rapid hypertonic glucose infusion in normal and diabetic subjects. Scand. J. clin. Lab. Invest. 28, 101-109 (1971)

12. Mogensen, C. E.: Glomerular filtration rate and renal plasma flow in normal and diabetic man during elevation of blood sugar levels. Scand. J. clin. Lab. Invest. 28, 183193 (1971)

13. Mogensen, C. E.: Kidney function and glomerular permeability to macromolecules in juvenile diabetes. Dan. med. Bull. 19, suppl. 3 (1972)

14. Mogensen, C. E.: Elevated glomerular filtration rate in insulin treated short-term diabetes. Acta med. scand. 194, 559-561 (1973)

15. Mogensen, C. E., Andersen, M. J. F.: Increased kidney size and glomerular filtration rate in early juvenile diabetes. Diabetes 22, 706-712 (1973)

16. Østerby, R., Gundersen, H. J. G.: Glomerular size and morphology in diabetes mellitus. I. Early Abnormalities. Diabetologia 11, 225-229 (1975)

17. Stalder, G., Schmid, R., Wolff, M. V.: Funktionelle Mikroangiopathie der Nieren beim behandelten Diabetes mellitus im Kindesalter. Dtsch. med. Wschr. 85, 346-350 (1960)

Dr. C. E. Mogensen

Medicinsk afdelning $M$

Århus Kommunehospital

DK- 8000 Ärhus C

Denmark 